\title{
Arterial Spin Labeling Magnetic Resonance Imaging
}

National Cancer Institute

\section{Source}

National Cancer Institute. Arterial Spin Labeling Magnetic Resonance Imaging. NCI

Thesaurus. Code C116450.

An application of functional MRI used to measure cerebral blood flow. ASL uses

magnetically labeled water as the tracer. 